\title{
The cost of living in mixed species populations: A fiddler crab example
}

\author{
Fábio H.C. Sanches ${ }^{\mathrm{a}, \mathrm{d}, *}$, Tânia M. Costa ${ }^{\mathrm{b}}$, Rodrigo E. Barreto ${ }^{\mathrm{a}}$, Patricia R.Y. Backwell ${ }^{\mathrm{c}}$ \\ a Department of Physiology, Institute of Biosciences of Botucatu, São Paulo State University (UNESP), CAUNESP, Botucatu, SP, Brazil \\ ${ }^{\mathrm{b}}$ Biosciences Institute, São Paulo State University (UNESP) - Coastal Campus, São Vicente, SP, Brazil \\ ${ }^{\mathrm{c}}$ Research School of Biology, The Australian National University, Canberra, ACT, Australia \\ ${ }^{\mathrm{d}}$ Center of Natural and Human Sciences, Federal University of ABC (CCNH/UFABC), Santo André, SP, Brazil
}

\section{A R T I C L E I N F O}

\section{Keywords:}

\section{Coalition}

\section{Competition}

Mate choice

Marine zonation

Sea level rise

\begin{abstract}
A B S T R A C T
Rising sea level is reducing the inter-tidal zone in many mangrove forests. This breaks down the normal species distribution patterns of fiddler crabs, with an increasing number of heterospecifics moving from adjacent zones into an area normally occupied by a single species. Here we examine the interspecific social and sexual interactions that have resulted. We show that male Austruca mjoebergi are just as likely to help their small conspecific neighbor fight off an intruder when the intruder is a conspecific or heterospecific male. It appears that keeping a known neighbor is preferable to having any new neighbor (even a heterospecific neighbor that would not compete for receptive females) since the costs of renegotiating territory boundaries would be the same whatever the species of the new neighbor. We also show that males court females of their own species just as vigorously as those of two heterospecific species. Courtship is costly, so the time and energy spent courting heterospecific females is wasted: a potentially high cost of living among heterospecifics.
\end{abstract}

\section{Introduction}

Climate change is already rapidly and irreversibly altering ecosystems (Hoegh-Guldberg and Bruno, 2010). Inter-tidal communities are especially vulnerable because the plants and animals that live there are adapted to a physiologically stressful environment. Marine zonation, with species restricted to very narrow bands, graphically illustrates that many individuals live within a few centimeters of their tolerance limits (Lovelock and Ellison, 2007). In this context, as sea levels comes up, mangrove communities might migrate landward up the inter-tidal gradient, with species maintaining their preferred depths, frequencies and durations of tidal inundation (Lovelock and Ellison, 2007). Unfortunately, there are now many human-induced barriers to migration: agriculture, roads, urban development and steeply sloped levees, what makes the upper inter-tidal zone one of the most vulnerable ecosystems (Gilman et al., 2008; Saintilan and Williams, 1999). In Australia, for example, four well-studied salt flats have already been reduced by rising sea level to $75 \%, 51 \%, 33 \%$ and $20 \%$ respectively of their original size (Gilman et al., 2007). Therefore, it is essential to understand the possible consequences of changes in species distribution related to rising sea level, especially those species that lives in monospecific zones and are now being forced to live in mixed-species areas.

Within mangrove ecosystems, fiddler crabs are arguably among the most ecologically important fauna, playing an essential role due to their bioturbation activities, resulting in ecosystem engineering (Cannicci et al., 2008; Citadin et al., 2016; Jones et al., 1994; Kristensen, 2008; Kristensen et al., 2012; Natálio et al., 2017; Penha-Lopes et al., 2009). Most species live in single-species populations due to specific habitat requirements (Booksmythe et al., 2011). They can be vulnerable to sea level rise, particularly those species that live in the upper inter-tidal zones. In this sense, rising sea levels and the concurrent landward migration is already eating away the mangroves and mudflats in Darwin Harbor. Over the past seven years, however, two fiddler crab species moving from adjacent zones have gradually but steadily been increasing in number within a previously monospecific population of Austruca mjoebergi (Backwell Personal communication). Tubuca elegans and, to a lesser extent Tubuca signata, are now commonly found within the A. mjoebergi population. This breakdown in the normal mosaic distribution pattern has potentially far reaching implications for the social and mating systems of these species. Species interactions, especially interference, can have profound effects on the timing and form of sexual signaling, even leading to evolutionary divergence in sexual traits (Martin et al., 1996).

From the social interactions point of view, competition for territories may be an important issue, since it is known that the most valuable resource for this group is its territory (Crane, 1975). Territory holders aggressively defend their burrow and an area in its surrounding against intruders. In addition, male $A$. mjoebergi have been shown to

\footnotetext{
* Corresponding author.

E-mail address: sanches.fabio@ufabc.edu.br (F.H.C. Sanches).
} 
form coalitions in which neighbors help each other to defend their territories from intruders (Backwell and Jennions, 2004): a male will assist his smaller neighbor to fight of an intruder if the intruder is larger than the resident (so the resident is likely to lose the fight) and if the helper is larger than the intruder (so the helper is likely to win the fight). Coalitions are likely to be due to by-product mutualism: the helper pays to retain an established neighbor and the neighbor keeps his territory (Backwell and Jennions, 2004). Coalition formation also occurs in T. elegans: males helped their conspecific neighbors in $50 \%$ of the attacks; they were significantly less likely to help a heterospecific (A. mjoebergi) neighbor, doing so in only $15 \%$ of attacks (Booksmythe et al., 2010). As T. elegans and T. signata are being squashed together in A. mjoebergi areas due to rising sea level, the extent to which A. mjoebergi can help conspecific neighbors against heterospecific intruders might be low, what potentially has implications in habitat ownership for this species.

Species interactions can also have several important effects on mate attraction. In A. mjoebergi, mating occurs over a five day period every two weeks (a semi-lunar cycle). Receptive females leave their territories and wander through the population of courting males, visiting several males before selecting a mate (see Reaney and Backwell, 2007). Courting males wave their enlarged claw in a species-specific wave pattern to attract the females (Crane, 1975). Females select their mates based on numerous criteria including claw size, wave rate, the production of temporally leading waves, male size and, ultimately, burrow quality (see Reaney and Backwell, 2007; Kahn et al., 2014 and refs therein). Waving is energetically expensive (Matsumasa and Murai, 2005) and indiscriminate courtship would impose substantial costs for A. mjoebergi males (Booksmythe et al., 2011). Time spent courting heterospecifics would reduce a male's opportunity to attract conspecific females. Earlier work has shown that, when a conspecific or a heterospecific (T. elegans) female is released in the population (one at a time), nearly every male they passed waved at them (Booksmythe et al., 2011). When presented with a conspecific and heterospecific (T. elegans) female simultaneously, males gave significantly more waves at conspecific females (Booksmythe et al., 2011). We do not know, however, whether males adjust wave rates at conspecific or heterospecific females or take greater risks by moving further away from their burrows when courting them.

Given the background, this study aims to examine the effect of mixed-species populations on the social interactions and mating success of $A$. mjoebergi. We specifically want to understand (i) whether a male A. mjoebergi is as likely to assist his neighbor when it is attacked by a conspecific or a heterospecific (either T. elegans or T. signata) male; and (ii) whether a male A. mjoebergi alters waves rate or travel greater distances from their burrows when courting a conspecific or heterospecific (either T. elegans or T. signata) female.

\section{Methods}

The study was conducted at East Point Reserve, Darwin, Australia $\left(12^{\circ} 24^{\prime} 31.89^{\prime \prime} \mathrm{S} 130^{\circ} 49^{\prime} 49.12^{\prime \prime} \mathrm{E}\right)$ from September to December 2015. Fiddler crabs (Note: Austruca mjoebergi was previously called Uca mjoebergi; Tubuca elegans was previously Uca elegans; Tubuca signata was previously Uca signata; see Shih et al., 2016 for details) were captured randomly in the population with the use of shovels. All individuals that were held until the use on experiments were housed individually in a cup containing $0.5 \mathrm{~cm}$ deep sea water in a shaded area to prevent them from overheating.

\subsection{Cooperation}

We captured males of the three species (A. mjoebergi, T. elegans and T. signata) from a distant part of the population and tethered them (a $3 \mathrm{~cm}$ length of cotton thread glued to their carapace and tied to a $3 \mathrm{~cm}$ long nail). We selected a pair of naturally occurring A. mjoebergi males, where one male was considerably larger than the other, and measured the distance between their burrows. We placed a tethered male (randomizing the species of intruder between trials) $3 \mathrm{~cm}$ away from the smaller resident, on the opposite side of the burrow to the larger resident. The tethered male was always intermediate in size between the two resident $A$. mjoebergi males. The tethered male could approach the burrow entrance but not enter the burrow of the smaller resident. The placement of the 'intruder' on the opposite side of the burrow to the larger resident ensured that the larger A. mjoebergi male was not fighting the 'intruder' in order to defend his own territory (see Backwell and Jennions, 2004). We scored helping behavior when the larger resident fought (physical contact between the claws of the 'helper' and 'intruder') the tethered intruder within 5 min of all males being surface active. After each trial, we captured and measured the claw length of all three males. Each male was used in only one trial. We did not use males with regenerated claws. Males intruders sample sizes were: $N=14$ to A. mjoebergi; $N=19$ to $T$. elegans; and $N=18$ to $T$. signata.

\subsection{Courtship}

We collected females of the three species and tethered them (a $3 \mathrm{~cm}$ length of cotton thread glued to their carapace and tied to a $3 \mathrm{~cm}$ long nail). We placed the nail $20 \mathrm{~cm}$ in front of an A. mjoebergi male burrow (this is the distance at which females make their choice: Callander et al., 2011). After the male emerged from his burrow, we counted the number of waved directed at the female and evaluate the distance the male moved towards the female while courting her within 5 min the male was surface active or until he touched the female with his legs during this time. Therefore, wave rate were evaluated by the number of waving per time of courting. We randomized the order of presentation of females between trials. After each trial, we captured and measured the male and female. Each female and male was used in only one trial. We did not use males with regenerated claws. Presented females sample sizes were: $N=20$ to A. mjoebergi; $N=10$ to T. elegans; and $N=14$ to T. signata.

\subsection{Data analyses}

We used one way ANOVA to examine the differences between the three species in the cooperation trials (distance between male burrows; claw lengths of helper, intruder and resident males; size difference between helper and intruder and between intruder and resident males) and the courtship trials (wave rate; distance travelled towards the female; female carapace widths; male claw lengths). In addition, we used a Likelihood ratio test to determine whether there was a difference in the number of times a male helped his neighbor when the intruder was an A. mjoebergi, a T. elegans or a T. signata male and to evaluate if there was difference between the 3 species in the number of females were touched by males. All these variables were homoscedastic (Levene test). The analyses were performed in SPSS version 23.0 (SPSS Inc., Armonk, NY, U.S.A.). The significance level was set at $\alpha<0.05$.

\subsection{Ethical note}

This research was approved by the Australian National University Animal Ethics Committee (permit A2015/54). We limited the handling and the amount of time each crab was used as much as possible. No crab was injured during the research, and they all continued their regular activities after release. The tethered crabs were released after the cotton thread had been cut as short as possible (such that the only thread remaining was fully glued to the carapace and would be lost at the next molt). The work was conducted under a research permit from the Darwin City Council (permit no. 2322876). 
Table 1

Distance between burrows $(\mathrm{cm})$, male sizes $(\mathrm{mm})$ and size differences for the three species of intruder $(\mathrm{mm})$. Data is presented as sample size $(\mathrm{N})$, mean $(\overline{\boldsymbol{x}})$, standard deviation of the mean (sd), degrees of freedom (df), F statistic from a one-way ANOVA (F), and probability (P)

\begin{tabular}{|c|c|c|c|c|c|c|c|}
\hline & Intruder & $\mathrm{N}$ & $\overline{\boldsymbol{x}}$ & Sd & Df & $\mathrm{F}$ & $\mathrm{P}$ \\
\hline \multirow[t]{3}{*}{ Distance between burrows } & A. mjoebergi & 14 & 15.36 & 2.81 & 2,48 & 0.93 & 0.4 \\
\hline & T. elegans & 19 & 16.71 & 2.73 & & & \\
\hline & T. signata & 18 & 16.04 & 2.96 & & & \\
\hline \multirow[t]{3}{*}{ Intruder claw length } & A. mjoebergi & 14 & 15.56 & 1.83 & 2,48 & 2.25 & 0.12 \\
\hline & T. elegans & 19 & 14.88 & 1.93 & & & \\
\hline & T. signata & 18 & 14.14 & 1.9 & & & \\
\hline \multirow[t]{3}{*}{ Helper claw length } & A. mjoebergi & 14 & 18.94 & 1.83 & 2,48 & 2.33 & 0.11 \\
\hline & T. elegans & 19 & 19.77 & 1.91 & & & \\
\hline & T. signata & 18 & 18.47 & 1.83 & & & \\
\hline \multirow[t]{3}{*}{ Resident claw length } & A. mjoebergi & 14 & 12.5 & 2.48 & 2,48 & 0.69 & 0.5 \\
\hline & T. elegans & 19 & 12.91 & 2.21 & & & \\
\hline & T. signata & 18 & 12.09 & 1.61 & & & \\
\hline \multirow[t]{3}{*}{ Size diff helper-intruder } & A. mjoebergi & 14 & 3.37 & 2.06 & 2,48 & 2.04 & 1.41 \\
\hline & T. elegans & 19 & 4.89 & 2.23 & & & \\
\hline & T. signata & 18 & 4.33 & 2.12 & & & \\
\hline \multirow[t]{3}{*}{ Size diff intruder-resident } & A. mjoebergi & 14 & 3.06 & 1.73 & 2,48 & 2.71 & 0.08 \\
\hline & T. elegans & 19 & 1.97 & 1.3 & & & \\
\hline & T. signata & 18 & 2.04 & 1.37 & & & \\
\hline
\end{tabular}

\section{Results}

\subsection{Cooperation}

The size of the intruder, helper and resident did not differ between the three trials type (when the intruder was an A. mjoebergi male, a $T$. elegans male, or a T. signata male), neither the size difference between the helper and intruder, nor the size difference between the intruder and the resident male differed between the three trial types. The distance between the burrows of the helper and resident males also did not differ between the three trial types (see Table 1). The three types of trials are therefore directly comparable.

A likelihood ratio test showed that there was no difference in the likelihood of help between the three trial types $\left(\mathrm{LR} \chi^{2}=3.41, \mathrm{df}=2\right.$, $P=0.18$ ). When the intruding male was a conspecific A. mjoebergi male, the neighbor helped a resident in 8 of the 14 trials (57\%). When the intruder was a heterospecific T. elegans male, the neighbor helped in 5 of the 19 trials $(26 \%)$. When the intruder was a heterospecific T. signata male, the neighbor helped in 6 of the 18 trials (33\%).

\subsection{Courtship}

Neither the size of the waving male nor the tethered female differed between the three types of trials (when the specie of presented female was A. mjoebergi, T. elegans, or T. signata, see Table 2). The three types of trials are therefore directly comparable. The wave rate did not differ between the three trial types and males moved an equivalent distance towards the female in all three trial types (Table 2).

A likelihood ratio test showed that there was no difference in the likelihood of touching females between the three trial types $\left(\mathrm{LR} \chi^{2}=0.56, \mathrm{df}=2, P=0.76\right)$. When the presented female was a conspecific A. mjoebergi, the male touched her with his legs in 13 of the 20 trials (65\%). When the female was a heterospecific T. elegans, the male touched her in 4 of the 10 trials (40\%). When the female was a heterospecific $T$. signata, the male touched her in 7 of the 14 trials (50\%).

\section{Discussion}

Our study indicated that it can be costly for fiddler crabs to live in
Table 2

The wave rate (waves/s), distance moved towards female $(\mathrm{cm})$, male claw length $(\mathrm{mm})$ and female carapace width $(\mathrm{mm})$ for trials with the three species of intruder. Data is presented as sample size $(\mathrm{N})$, mean $(\overline{\boldsymbol{x}})$, standard deviation of the mean (sd), degrees of freedom (df), F statistic from a one-way ANOVA (F), and probability (P).

\begin{tabular}{llllllll}
\hline & Intruder & $\mathrm{N}$ & $\overline{\boldsymbol{x}}$ & $\mathrm{Sd}$ & $\mathrm{df}$ & $\mathrm{F}$ & $\mathrm{P}$ \\
\hline Wave rate & A. mjoebergi & 20 & 0.22 & 0.07 & 2,41 & 0.04 & 0.97 \\
& T. elegans & 10 & 0.21 & 0.07 & & & \\
& T. signata & 14 & 0.21 & 0.06 & & & \\
Distance moved towards & A. mjoebergi & 20 & 16.25 & 4.48 & 2,41 & 1.26 & 0.29 \\
female & T. elegans & 10 & 14.50 & 5.38 & & & \\
Male claw length & T. signata & 14 & 16.25 & 4.04 & & & \\
& A. mjoebergi & 20 & 17.28 & 3.23 & 2,41 & 1.36 & 0.27 \\
& T. elegans & 10 & 18.90 & 2.13 & & & \\
Female carapace width & T. signata & 14 & 18.40 & 2.42 & & & \\
& A. mjoebergi & 20 & 9.59 & 0.83 & 2,41 & 2.98 & 0.06 \\
& T. elegans & 10 & 9.96 & 1.36 & & & \\
& T. signata & 14 & 8.96 & 1.04 & & & \\
\hline
\end{tabular}

mixed-species areas, with implications for the social and mating systems of this group. The identity of intruder species did not affect male coalition formation. Thus, the probability of losing territory for a conspecific or a heterospecifics is the same, and this could have consequences in terms of habitat loss, and therefore associated resource loss to intruder species. Furthermore, the species identity of females did not affect males courting behaviors, causing them to waste time and energy and exposing themselves to risks while courting females that they cannot mate.

Males of $A$. mjoebergi are just as likely to help their small conspecific neighbors fight off intruders when the intruders are conspecific or heterospecific males. When the intruder is intermediate in size between the small resident that he is attacking and it's larger neighbor (see Backwell and Jennions, 2004), then it is irrelevant whether the intruder is a conspecific or a heterospecific male. Austruca mjoebergi is smaller than the two heterospecific species: the average size of $A$. mjoebergi males is $17.8 \pm 0.12 \mathrm{~mm}$ claw length (Morrell et al., 2005); T. elegans have a mean claw length of $21.07 \pm 0.31 \mathrm{~mm}$ (Booksmythe et al., 2010); and T. signata have claws that are $21.0 \pm 0.31 \mathrm{~mm}$ long (Booksmythe et al., 2008). This difference in size means that there would be fewer occasions when a heterospecific intruder had a size intermediate between a small and a large A. mjoebergi, so fewer occasions when helping behavior would occur (in comparison to intrusions by conspecific males). However, when the required size patterns holds, it appears that $A$. mjoebergi males are prepared to pay a cost for keeping their small conspecific neighbor. The opposite would be expected once it is possible that a heterospecific neighbor would be preferable to a conspecific since they would not compete for the attention of matesearching females. Alternatively, it is probable that keeping a known neighbor is preferable to having any new neighbor since the costs of renegotiating territory boundaries would be the same whatever the species of the new neighbor.

One of the most valuable resources for this group is its territory and survival depends on holding it (Crane, 1975). The consequences of losing the territory are the decrease in mating success and the increased of both threat of predation and chance of dehydration (which is especially important since the mudflat can reach temperatures of $50{ }^{\circ} \mathrm{C}$ at midday; Munguia et al., 2017). If A. mjoebergi loses territory to conspecifics, the consequences would be more at individual level instead of species level, since the territory and associated resources would not be lost to a larger and more competitively superior species. On the other hand, losing fights against heterospecifics it would have more costly consequences to the species, once this might impact the number of resources and area available to A. mjoebergi, allowing heterospecific individuals to usurp their habitat.

The males of Austruca mjoebergi are also non-discriminatory in their 
courtship of females: they wave at the same rate and move an equivalent distance away from their burrows when courting conspecific and heterospecific females. They also are just as likely to touch with the legs conspecific or heterospecific females. Why do males not discriminate between females of different species? The most obvious answer is that they are unable to recognize conspecific females. We know, however, that this is not true: when presented with a conspecific and a heterospecific female simultaneously (an event that is unlikely to occur naturally), males waved faster and for longer periods of time to the conspecific female (Booksmythe et al., 2011). From this, we know that they can comparatively differentiate between conspecific and heterospecific females. We suggest that males court indiscriminately because the operational sex ratio is very male biased (45:1; Reading and Backwell, 2007). The low probability of encountering a receptive female may favor indiscriminate courtship since the lost time and energy of courting a heterospecific female may be outweighed by the chance of not courting a conspecific female (see Booksmythe et al., 2011). Additionally, fiddler crabs females irrespectively of the species may have a sexual key stimulus to males, triggering court behaviors to conspecifics and heterospecifics.

Changes in species behavior can potentially affect their distributions and thus alter community composition (Kearney, 2006). It is important to understand the behavioral interactions between species that are forced to coexist due to habitat loss, particularly due to the effects of sea level rise (Montoya and Raffaelli, 2010). In addition, understanding the effect of sea-lever rise and the consequent overlap of species can give us a greater understanding of the potential outcomes from unabated climate change. Herein, we concluded that fiddler crabs pays a high cost by environmental shifts associated with habitat loss due to rising sea level, and this has far reaching implications for the social and mating systems of this group. This exposes the vulnerability of communities from intertidal areas, especially those species that have mosaic distribution pattern limited by competition in different costal ecosystems. Lastly, climate change is predicted to have more detrimental fitness consequences for tropical ectotherms than any other group (Dillon et al., 2010), so future works should focus on specific behavioral process from several species that potentially can be affected in this context.

\section{Acknowledgements}

We thank the North Australian Research Unit for facilities and Nina Svedin and Daniela M. Perez for help in the field. This research received financial support from an Australian Research Council Discovery Grant (ARC DP120101427). F. H. C. Sanches received financial support through a scholarship from PDSE - CAPES (Process: 99999.003008/ 2015-00).

\section{References}

Backwell, P.R.Y., Jennions, M.D., 2004. Coalition among male fiddler crabs. Nature 430, 417. http://dx.doi.org/10.1038/nature02822.

Booksmythe, I., Detto, T., Backwell, P.R., 2008. A field guide to the fiddler crabs of east point reserve, Darwin, northern territory. North. Territ. Nat. 20, 26-33.

Booksmythe, I., Jennions, M.D., Backwell, P.R.Y., 2010. Investigating the "dear enemy" phenomenon in the territory defence of the fiddler crab, Uca mjoebergi. Anim. Behav. 79, 419-423. http://dx.doi.org/10.1016/j.anbehav.2009.11.020.

Booksmythe, I., Jennions, M.D., Backwell, P.R.Y., 2011. Male fiddler crabs prefer conspecific females during simultaneous, but not sequential, mate choice. Anim. Behav. 81, 775-778. http://dx.doi.org/10.1016/j.anbehav.2011.01.009.

Callander, S., Jennions, M.D., Backwell, P.R.Y., 2011. Female choice over short and long distances: neighbour effects. Behav. Ecol. Sociobiol. 65, 2071-2078. http://dx.doi. org/10.1007/s00265-011-1216-0.
Cannicci, S., Burrows, D., Fratini, S., Smith, T.J., Offenberg, J., Dahdouh-Guebas, F., 2008. Faunal impact on vegetation structure and ecosystem function in mangrove forests: a review. Aquat. Bot. 89, 186-200. http://dx.doi.org/10.1016/j.aquabot. 2008.01.009.

Citadin, M., Costa, T.M., Netto, S.A., 2016. The response of meiofauna and microphytobenthos to engineering effects of fiddler crabs on a subtropical intertidal sandflat. Austral Ecol. 41, 572-579. http://dx.doi.org/10.1111/aec.12346.

Crane, J., 1975. Fiddler Crabs of the World. Ocypodae: Genus Uca. Princenton University Press, New Jersey.

Dillon, M.E., Wang, G., Huey, R.B., 2010. Global metabolic impacts of recent climate warming. Nature 467, 704-706. http://dx.doi.org/10.1038/nature09407.

Gilman, E., Ellison, J., Coleman, R., 2007. Assessment of mangrove response to projected relative sea-level rise and recent historical reconstruction of shoreline position. Environ. Monit. Assess. 124, 105-130. http://dx.doi.org/10.1007/s10661-0069212-y.

Gilman, E.L., Ellison, J., Duke, N.C., Field, C., 2008. Threats to mangroves from climate change and adaptation options: a review. Aquat. Bot. 89, 237-250. http://dx.doi.org/ 10.1016/j.aquabot.2007.12.009.

Hoegh-Guldberg, O., Bruno, J.F., 2010. The impact of climate chsange on the World's marine ecosystems. Science 80 (328), 1523-1528. http://dx.doi.org/10.1126/ science. 1189930 .

Jones, C., Lawton, J., Shachak, M., 1994. Organisms as ecosystem engineers. Oikos 69, 373-386.

Kahn, A.T., Holman, L., Backwell, P.R.Y., 2014. Female preferences for timing in a fiddler crab with synchronous courtship waving displays. Anim. Behav. 98, 35-39. http:// dx.doi.org/10.1016/j.anbehav.2014.09.028.

Kearney, M., 2006. Habitat, environment and niche: what are we modelling? Oikos 115, 186-191.

Kristensen, E., 2008. Mangrove crabs as ecosystem engineers; with emphasis on sediment processes. J. Sea Res. 59, 30-43. http://dx.doi.org/10.1016/j.seares.2007.05.004.

Kristensen, E., Penha-Lopes, G., Delefosse, M., Valdemarsen, T., Quintana, C.O., Banta, G.T., 2012. What is bioturbation? The need for a precise definition for fauna in aquatic sciences. Mar. Ecol. Prog. Ser. 446, 285-302. http://dx.doi.org/10.3354/ meps09506.

Lovelock, C., Ellison, J., 2007. Vulnerability of Mangroves and Tidal Wetlands of the Great Barrier Reef to Climate Change. In: Climate Change and the Great Barrier Reef: A Vulnerability Assessment, pp. 237-269.

Martin, P.R., Fotheringham, J.R., Ratcliffe, L., Robertson, R.J., 1996. Response of American redstarts (suborder Passeri) and least flycatchers (suborder Tyranni) to heterospecific playback: the role of song in aggressive interactions and interference competition. Behav. Ecol. Sociobiol. 39, 227-235. http://dx.doi.org/10.1007/ s002650050285.

Matsumasa, M., Murai, M., 2005. Changes in blood glucose and lactate levels of male fiddler crabs: effects of aggression and claw waving. Anim. Behav. 69, 569-577. http://dx.doi.org/10.1016/j.anbehav.2004.06.017.

Montoya, J.M., Raffaelli, D., 2010. Climate change, biotic interactions and ecosystem services. Philos. Trans. R. Soc. B Biological Sci. 365, 2013-2018. http://dx.doi.org/ 10.1098/rstb.2010.0114.

Morrell, L.J., Backwell, P.R.Y., Metcalfe, N.B., 2005. Fighting in fiddler crabs Uca mjoebergi: what determines duration? Anim. Behav. 70, 653-662. http://dx.doi.org/ 10.1016/j.anbehav.2004.11.014.

Munguia, P., Backwell, P.R.Y., Darnell, M.Z., 2017. Thermal constraints on microhabitat selection and mating opportunities. Anim. Behav. 123, 259-265. http://dx.doi.org/ 10.1016/j.anbehav.2016.11.004.

Natálio, L.F., Pardo, J.C.F., Machado, G.B.O., Fortuna, M.D., Gallo, D.G., Costa, T.M., 2017. Potential effect of fiddler crabs on organic matter distribution: a combined laboratory and field experimental approach. Estuar. Coast. Shelf Sci. 184, 158-165. http://dx.doi.org/10.1016/j.ecss.2016.11.007.

Penha-Lopes, G., Bartolini, F., Limbu, S., Cannicci, S., Kristensen, E., Paula, J., 2009. Are fiddler crabs potentially useful ecosystem engineers in mangrove wastewater wetlands? Mar. Pollut. Bull. 58, 1694-1703. http://dx.doi.org/10.1016/j.marpolbul. 2009.06.015.

Reading, K.L., Backwell, P.R.Y., 2007. Can beggars be choosers? Male mate choice in a fiddler crab. Anim. Behav. 74, 867-872. http://dx.doi.org/10.1016/j.anbehav.2006. 09.025.

Reaney, L.T., Backwell, P.R.Y., 2007. Temporal constraints and female preference for burrow width in the fiddler crab, Uca mjoebergi. Behav. Ecol. Sociobiol. 61, 1515-1521. http://dx.doi.org/10.1007/s00265-007-0383-5.

Saintilan, N., Williams, R.J., 1999. Mangrove transgression into saltmarsh environments in South-East Australia. Glob. Ecol. Biogeogr. 8, 1999. http://dx.doi.org/10.1046/j. 1365-2699.1999.00133.x.

Shih, H., Ng, P.K.L., Davie, P.J.F., Schubart, C.D., Türkay, M., 2016. Systematics of the family Ocypodidae Rafinesque, 1815 (Crustacea: Brachyura), based on phylogenetic relationships, with a reorganization of subfamily rankings and a review of the taxonomic status of Uca Leach, 1814, sensu lato and its subgenera. Raffles Bull. Zool. 64, 139-175. 